\title{
Using ecological and field survey data to establish a national list of the wild bee pollinators of crops
}

Louise A. Hutchinson $^{\text {a,* }}$, Tom H. Oliver ${ }^{\mathrm{b}}$, Tom D. Breeze ${ }^{\mathrm{a}}$, Emily J. Bailes ${ }^{\mathrm{c}, \text { ad, ae }}{ }^{\text {, Lisa Brünjes }}{ }^{\mathrm{d}}$, Alistair J. Campbell ${ }^{\mathrm{e}}$, Andreas Erhardt ${ }^{\mathrm{f}}, \mathrm{G}$. Arjen de Groot $^{\mathrm{g}}{ }^{\text {, Rita Földesi }}{ }^{\mathrm{h}}$, Daniel García ${ }^{\mathrm{i}}$, Dave Goulson $^{\mathrm{j}}$, Hélène Hainaut ${ }^{\mathrm{k}}$, Peter A. Hambäck ${ }^{1}$, Andrea Holzschuh ${ }^{\mathrm{m}}$, Frank Jauker ${ }^{\mathrm{n}}$, Björn K. Klatt ${ }^{\mathrm{o}, \mathrm{p}}$, Alexandra-Maria Klein ${ }^{\mathrm{q}}$, David Kleijn ${ }^{\mathrm{r}}$, Anikó Kovács-Hostyánszki ${ }^{\mathrm{s}}$, Elena Krimmer ${ }^{\mathrm{m}}$, Megan McKerchar ${ }^{\mathrm{t}}$, Marcos Miñarro ${ }^{\mathrm{u}}$, Benjamin B. Phillips ${ }^{\mathrm{v}}$, Simon G. Potts ${ }^{\mathrm{a}}$, Gesine Pufal $^{\mathrm{q}}$, Rita Radzevičiūte ${ }^{\mathrm{w}, \mathrm{x}, \mathrm{y}}$, Stuart P.M. Roberts ${ }^{\mathrm{a}}$, Ulrika Samnegård ${ }^{1, \mathrm{o}}$, Jürg Schulze ${ }^{\mathrm{z}}$, Rosalind F. Shaw ${ }^{\mathrm{v}}$, Teja Tscharntke ${ }^{\mathrm{aa}}$, Nicolas J. Vereecken ${ }^{\mathrm{k}}$, Duncan B. Westbury $^{\mathrm{t}}$, Catrin Westphal ${ }^{\mathrm{p}}$, Alexander Wietzke ${ }^{\mathrm{ab}}$, Ben A. Woodcock ${ }^{\mathrm{ac}}$, Michael P. D. Garratt ${ }^{\mathrm{a}}$

\footnotetext{
${ }^{a}$ Centre for Agri-Environmental Research, School of Agriculture, Policy and Development, University of Reading, United Kingdom

${ }^{\mathrm{b}}$ School of Biological Sciences, University of Reading, United Kingdom

${ }^{\mathrm{c}}$ Department of Molecular Biology and Biotechnology, University of Sheffield, United Kingdom

${ }^{\mathrm{d}}$ Plant Breeding Methodology, Department of Crop Sciences, University of Göttingen, Göttingen, Germany

e Embrapa Amazônia Oriental, Travessa Enéas Pinheiro, Marco, Belém CEP 66095-903, Pará, Brazil

${ }^{\mathrm{f}}$ University of Basel, Department of Environmental Sciences, Botany, Schönbeinstrasse 6, CH-4056 Basel, Switzerland

${ }^{\mathrm{g}}$ Wageningen Environmental Research, Wageningen UR, P.O. Box 47, 6700 AA Wageningen, The Netherlands

${ }^{\mathrm{h}}$ Lendület Ecosystem Services Research Group, Institute of Ecology and Botany, Centre for Ecological Research, 2163 Vácrátót, Hungary

${ }^{\text {i }}$ Depto. Biología de Organismos y Sistemas, Universidad de Oviedo, and Unidad Mixta de Investigación en Biodiversidad (CSIC-Uo-PA), C/Catedrático Rodrigo Uría s/n, E-33006 Oviedo, Asturias, Spain

${ }^{\mathrm{j}}$ School of Life Sciences, University of Sussex, Brighton, United Kingdom

${ }^{\mathrm{k}}$ Agroecology Lab, Université Libre de Bruxelles (ULB), Boulevard du Triomphe CP 264/2, B-1050 Brussels, Belgium

${ }^{1}$ Department of Ecology, Environment and Plant Sciences, Stockholm University, 10691 Stockholm, Sweden

m Animal Ecology and Tropical Biology, Biocenter, University of Würzburg, 97074 Würzburg, Germany

${ }^{\mathrm{n}}$ Department of Animal Ecology, Justus Liebig University Giessen, Heinrich-Buff-Ring 26-32, D-35392 Giessen, Germany

${ }^{\circ}$ Department of Biology, Lund University, SE-223 62 Lund, Sweden

${ }^{\mathrm{p}}$ Functional Agrobiodiversity, Department of Crop Sciences, University of Göttingen, Göttingen, Germany

${ }^{\mathrm{q}}$ Nature Conservation and Landscape Ecology, Faculty of Environment and Natural Resources, University of Freiburg, Freiburg, Germany

${ }^{\mathrm{r}}$ Plant Ecology and Nature Conservation Group, Wageningen University, Droevendaalsesteeg 3a, 6708PB Wageningen, The Netherlands

${ }^{\mathrm{s}}$ Lendület Ecosystem Services Research Group, Institute of Ecology and Botany, Centre for Ecological Research, Alkotmány str. 2-4, 2163 Vácrátót, Hungary

${ }^{t}$ School of Science \& the Environment, University of Worcester, Worcester, United Kingdom

"Servicio Regional de Investigación y Desarrollo Agroalimentario (SERIDA), Apdo. 13, E-33300 Villaviciosa, Asturias, Spain

${ }^{\mathrm{v}}$ Environment and Sustainability Institute, University of Exeter, Penryn Campus, Penryn, Cornwall TR10 9FE, United Kingdom

${ }^{\mathrm{w}}$ General Zoology, Institute for Biology, Martin Luther University Halle-Wittenberg, Hoher Weg 8, D-06120 Halle (Saale), Germany

${ }^{\mathrm{x}}$ Molecular Evolution and Animal Systematics, Institute for Biology, Leipzig University, Talstraße 33, D-04103 Leipzig, Germany

${ }^{y}$ Life Sciences Center, Vilnius University, Sauletekio al. 7, LT-10223 Vilnius, Lithuania

${ }^{\mathrm{z}}$ Agency for Environment and Energy Canton Basel-City, Hochbergerstr. 157, 4019 Basel, Switzerland

aa Agroecology, Dept. of Crop Sciences, University of Göttingen, Grisebachstrasse 6, 37077 Göttingen, Germany

${ }^{\mathrm{ab}}$ Plant Ecology and Ecosystems Research, University of Goettingen, Untere Karspüle 2, 37073 Göttingen, Germany

${ }^{\text {ac }}$ UK Centre for Ecology \& Hydrology, Crowmarsh Gifford, Wallingford, Oxfordshire, United Kingdom

${ }^{\text {ad }}$ Department of Plant Sciences University of Cambridge, Cambridge, UK

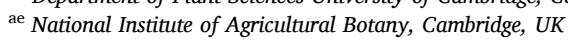

\footnotetext{
* Corresponding author.

E-mail address: 1.hutchinson@pgr.reading.ac.uk (L.A. Hutchinson).
} 


\section{A R T I C L E I N F O}

\section{Keywords:}

Agri-environment Schemes

Apple

Biodiversity

Crop pollination

Dominant pollinators

Ecosystem services

Field bean

Oilseed rape

Rare species

Strawberry

\begin{abstract}
A B S T R A C T
The importance of wild bees for crop pollination is well established, but less is known about which species contribute to service delivery to inform agricultural management, monitoring and conservation. Using sites in Great Britain as a case study, we use a novel qualitative approach combining ecological information and field survey data to establish a national list of crop pollinating bees for four economically important crops (apple, field bean, oilseed rape and strawberry). A traits data base was used to establish potential pollinators, and combined with field data to identify both dominant crop flower visiting bee species and other species that could be important crop pollinators, but which are not presently sampled in large numbers on crops flowers. Whilst we found evidence that a small number of common, generalist species make a disproportionate contribution to flower visits, many more species were identified as potential pollinators, including rare and specialist species. Furthermore, we found evidence of substantial variation in the bee communities of different crops. Establishing a national list of crop pollinators is important for practitioners and policy makers, allowing targeted management approaches for improved ecosystem services, conservation and species monitoring. Data can be used to make recommendations about how pollinator diversity could be promoted in agricultural landscapes. Our results suggest agri-environment schemes need to support a higher diversity of species than at present, notably of solitary bees. Management would also benefit from targeting specific species to enhance crop pollination services to particular crops. Whilst our study is focused upon Great Britain, our methodology can easily be applied to other countries, crops and groups of pollinating insects.
\end{abstract}

\section{Introduction}

Insect pollination is key to global agricultural productivity (IPBES, 2016) due to growing demand for entomophilous crops (Godfray and Garnett, 2014). The nutritional and economic importance of insect pollinated crops (Vanbergen et al., 2014), and the inability of managed pollinators (e.g., Apis mellifera) to meet service demand, mean agriculture is highly dependent upon wild pollinators (Aizen and Harder, 2009; Breeze et al., 2014). Yet conventional agricultural practices are a key driver of pollinator declines (Senapathi et al., 2015). Whilst agri-environment scheme options have had positive impacts (Tonietto and Larkin, 2018), most benefit a limited suite of common species (Scheper et al., 2013) and homogeneous communities provide less reliable pollination services (Grab et al., 2019). Currently agri-environment schemes tend preferentially to benefit bumblebee populations (Wood et al., 2015a, 2015b, 2016a, 2016b), yet solitary bee species are more important pollinators of some crops (Woodcock et al., 2013). As such, current agri-environment schemes may not be optimally designed to increase pollination services to many crops. Identifying key pollinating species to individual crops, and ones which may provide additional pollination and insurance against declines in other species, would help inform agricultural management for bee pollinators (Garratt et al., 2014a). Yet there is insufficient information on bee communities for many crops (Kremen and Chaplin-Kramer, 2007) and no studies have attempted to establish a 'national list' of crop pollinators to advise management or monitoring programmes.

Whilst the majority of crop flower visitation is attributed to a small proportion of bee species (Kleijn et al., 2015), species-rich communities have been shown to positively influence crop yields and pollination service stability (Hoehn et al., 2008; Garibaldi et al., 2011; Martins et al., 2015; Dainese et al., 2019; Woodcock et al., 2019). Biodiversity conservation and ecosystem service management are often seen as distinct objectives (Sutter et al., 2017), however management that only targets common crop pollinators will not safeguard production if it fails to encompass species that supplement service provision (Fijen et al., 2018). High species turnover means that diverse communities, including rare and specialist species, are required to maintain crop pollination service at regional scales (Winfree et al., 2018). With climate change reducing the occupancy and richness of some wild bee species (Soroye et al., 2020), supporting wider species diversity may be crucial for crop pollination service stability under the substantial future environmental change that is predicted (Oliver et al., 2015; Dainese et al., 2019). Additionally, different crops have distinct pollinator communities and it will be beneficial to identify the pollinating taxa of individual crops and target management accordingly (Garratt et al., 2014a). Furthermore, a national list of crop pollinators can inform monitoring schemes to ensure they include important crop pollinating species (Carvell et al., 2017; Garratt et al., 2019).

In order to inform pollinator management and monitoring, our study aimed to compile the bee species visiting four crops: apple (Malus domestica), field bean (Vicia faba), oilseed rape (Brassica napus) and strawberry (Fragaria $x$ ananassa). Insect pollination has been shown to enhance yield quantity and quality in all four crops (Bartomeus et al., 2014; Garratt et al., 2014b). Additionally, they differ in flower phenology and morphology (Garibaldi et al., 2015) and likely show corresponding differences in their pollinator community composition (Garratt et al., 2014a). We use sites in Great Britain as a case study because its bee fauna is comprehensively described and their occupancy is well recorded over a long time period (Powney et al. 2019). We compiled a list of all British bee species and their available physiological and ecological traits, and combined it with field survey data in order to devise an approach to generate lists of (i) definite flower visitors to each crop (ii) likely flower visitors, which are expected to also contribute to crop pollination (iii) possible crop flower visitors whose contribution to pollination is not well understood and merits further investigation. Our aim was to compile these lists for reference purposes, but not to statistically compare pollinator communities between crops, due to the unstandardised nature of the datasets used to generate the lists of bee species. Additionally, we identify dominant crop pollinating species, and asses the contribution of wild bees compared to honey bees for crop flower visitation.

\section{Materials and methods}

\subsection{Potential crop pollinators}

First, a species database of all extant, resident wild bee species in Great Britain was established using the most recent checklist of UK species (Else et al., 2016). For each species, data on the following were collated: flight period (months); sociality (cleptoparasite, eusocial or solitary); lecty (oligolectic or polylectic, including if any of the target crop plant families are visited for pollen and/or nectar), tongue length (short/long), geographic coverage (distribution and habitat) (based on trait information compiled by Stuart Roberts for the EU- FP6 ALARM-project and BWARS, 2020) and conservation status (Webb et al., 2018). Potential crop pollinators, as defined here, are those bee species which, based upon these ecological traits, such as flight period, lecty, sociality and tongue length, could pollinate our target crops. Habitat specialists that are not coincident with cropland were initially excluded i.e., primarily coastal, heathland species. The known floral ecology of 
each species was then used to refine lists for each crop. Cleptoparasitic species, species that are oligolectic on plant families other than the target crop or polylectic, but not documented as foraging on the relevant plant family for pollen or nectar and species whose flight period does not overlap with the relevant crops flowering period were excluded. For field bean, only 'long-tongued' species (Michener, 2000) were considered as its flowers have deep corollas and most visits by 'short-tongued' species involve nectar robbing rather than legitimate visitation (Garratt et al., 2014a).

\subsection{Field survey data}

Field studies were sourced through literature searches in google scholar and existing datasets held by the authors. Fifty-seven datasets from across England, Scotland and eight other European countries were available to combine with the potential crop pollinator lists in order to establish shortlists of crop flower visitors (Fig. 1 and Table S3).

Lists of bee species recorded in crop fields were compiled using three types of survey data:

i) British flower visitation studies (e.g. transect walks, observation plots).

ii) British pan trap studies in crop fields.

iii) Other European flower visitation studies (used to validate crop flower visitation for species sampled in British pan traps only).

For every bee species the total number of reported legitimate flower visits and number of studies recorded in were calculated for each crop. If studies did not include quantitative data then a conservative approach was taken whereby each bee species listed was taken as representing a single crop flower visit. As pan trap catches do not provide information on floral associations (Westphal et al., 2008), these data were only used, in combination with trait data, to generate the list of possible pollinators.

\subsection{Crop flower visitors}

The lists of potential crop pollinators were combined with the field survey data to categorize bee species into one of three flower visitor categories (Fig. 2; Full details in Supplementary Methods 1):

i) Definite Flower Visitors - Species recorded visiting crop flowers in British flower visitation studies.

ii) Likely Flower Visitors - Species recorded in British pan trap crop studies and recorded as making at least two flower visits in other European studies.

iii) Possible Flower Visitors - Species only recorded in British pan trap studies, or in other European flower visitor studies only, and classified as a potential crop flower visitor.

\subsection{Dominant crop flowers visitors}

As visitation rate to crop flowers is a good proxy of relative contribution to pollination service delivery (Vázquez et al., 2005), we identified the dominant British flower visiting bee species per crop by approximating the species attributed with a combined total of $80 \%$ of flower visits, the proportion identified as corresponding to the dominant flower visitors by Kleijn et al. (2015). Only British flower visitation datasets where bee species were either all identified to species or genus were included in the analysis (Supplementary Methods 2). Additionally, we calculated the average proportion of visits to crop flowers attributed to wild bees compared to honey bees for all crops (Supplementary Methods 2).

\section{Results}

\subsection{Potential crop pollinators}

A preliminary list of 229 extant, resident British wild bee species was compiled. Of those 132 species were excluded due to ecological and

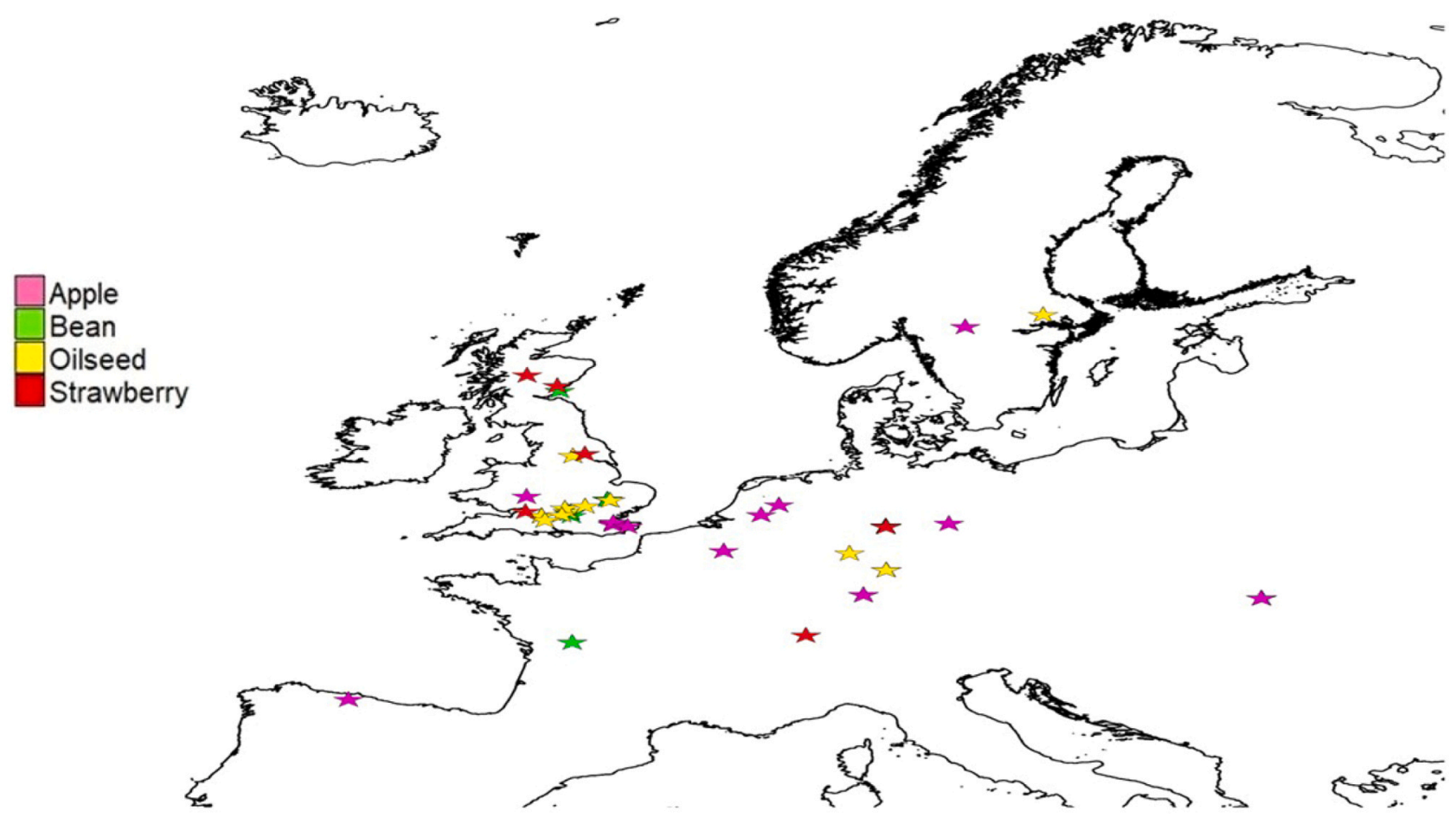

Fig. 1. Map of Europe, showing the countries from which field studies were sourced for each crop. 


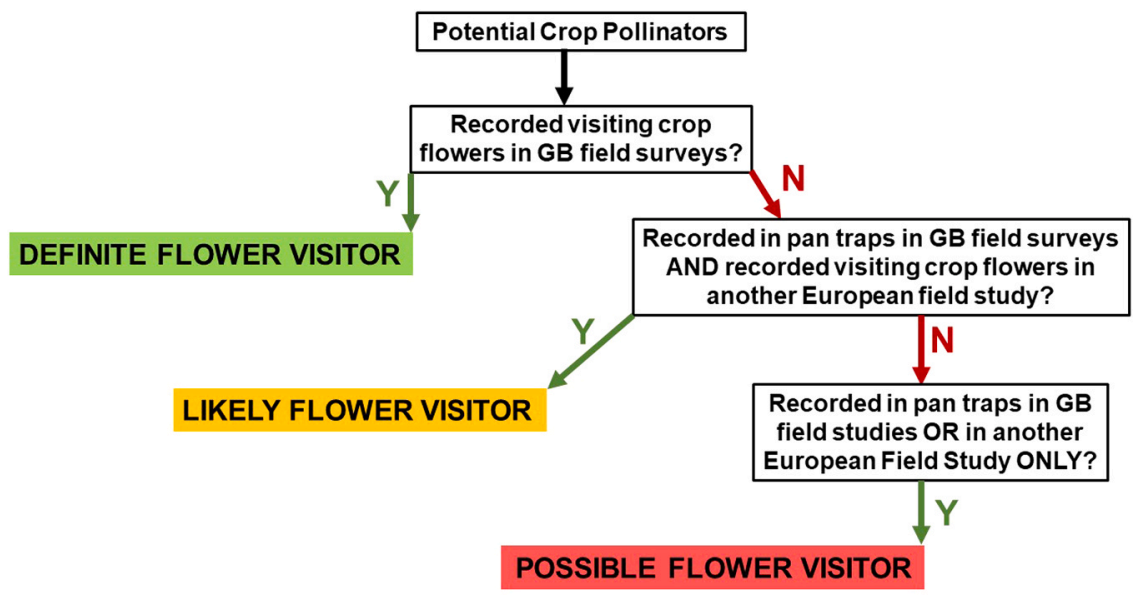

Fig. 2. Methodology by which bee species were categorised as definite, likely and possible flower visitors.

lecty traits that were deemed incompatible with these bees being present in crop fields and/or crop flower visitors (Table S1). Four species were treated as an aggregate - Bombus terrestris aggregate - due to the difficulties of separating their workers in the field (Wolf et al., 2010; Bossert, 2015). Therefore, a total of 97 species were initially identified as potential crop pollinators. Accounting for their documented foraging ecology and flight period, the following number of species were considered as potential pollinators per crop: apple- 83 , bean- 30 , oilseed60, and strawberry - 90 (Table S2).

\subsection{Field survey data}

The total number of studies sourced per crop were as follows: apple 17; bean -10 ; oilseed -19 ; strawberry -11 . The number of studies per survey type for each crop is provided in Fig. S1.

\subsection{Crop flower visitors}

Seventy-three species from ten genera where categorised as flower visitors of one or more crops, 63 of which were recorded in British crop field studies (Table 1, Fig. 3). Fourteen species were included in flower visitor categories that were not initially identified as potential crop pollinators. Ten of those were widely polylectic Bombus or Lasioglossum species, all recorded in oilseed datasets, but not documented in the literature as foraging on Brassicaceae. The remaining species were three short-tongued Andrena species recorded visiting bean flowers, two of which are oligolectic on Fabaceae and a Colletes species, recorded in a single strawberry dataset, that is documented as being oligolectic on another plant family. The majority of species identified as potential pollinators, but not recorded in crop field surveys were either rare species or polylectic species documented as having distinct preferences for plant families other than the target crop. The remaining species were overwhelmingly smaller species from the genera Hylaeus and Lasioglossum or cavity nesting Megachilidae. Most species identified as crop flower visitors were geographically widespread (BWARS, 2020) and polylectic species. However, a quarter $(n=18)$ of species included in

Table 1

Number of bee species, based upon field datasets and trait information, that were assigned to each category of flower visitor per crop.

\begin{tabular}{llccc}
\hline \multirow{2}{*}{ Crop } & \multicolumn{2}{l}{ Flower visitor category } & Total \\
\cline { 2 - 4 } & Definite & Likely & Possible & \\
\hline Apple & 19 & 13 & 25 & 57 \\
Field Bean & 11 & 0 & 3 & 14 \\
Oilseed Rape & 37 & 11 & 3 & 51 \\
Strawberry & 9 & 6 & 18 & 33 \\
\hline
\end{tabular}

flower visitor categories, currently have a designated conservation status in Britain. Full details of all species in crop flower visitor categories are given in Tables S4a-d and S5a-S8d.

\subsubsection{Apple}

All five British apple flower visitor studies recorded every bee to species level. Andrena were the most speciose genus of flower visitor, both overall $(n=22)$ and in the definite flower visitor category $(\mathrm{n}=10)$. Bombus species were the next most commonly represented genus in the latter category $(n=6)$, but were less frequent overall $(\mathrm{n}=9)$ than Lasioglossum species $(\mathrm{n}=16)$. Within the definite flower visitor category $80 \%$ of flower visits were attributed to eight species, only half of which were recorded in all studies. Most likely and possible flower visitors were Andrena or Lasioglossum species.

\subsubsection{Bean}

Three of the five British bean flower visitor studies recorded all bee to species level, the remainder only recorded Bombus to species, which was both the most common genus overall $(n=9)$ and in the definite flower visitor category $(\mathrm{n}=7)$. Three short-tongued Andrena sp. were identified as definite flower visitors, but all were recorded as very low numbers of flower visits $(\leq 10)$. Four Bombus species and Anthophora plumipes accounted for $95 \%$ of all visits recorded in British flower visitation studies. However, all the A. plumipes records derived from one study (Bond and Kirby, 1999) carried out at a single site. The four Bombus were the only species recorded in four or more studies. No species met the criteria for the likely flower visitor category. The possible flower visitor category included two Bombus and one Osmia species.

\subsubsection{Oilseed}

Six of the nine British oilseed flower visitor studies recorded bees to species level, but only two included quantitative data on all bee species. Andrena was the most speciose genus of bee, both overall $(\mathrm{n}=27)$ and within the definite flower visitor category $(\mathrm{n}=15)$. Bombus and Lasioglossum species were equally represented in the definite flower visitor category $(n=9)$, but Lasioglossum were more frequent overall $(n=14)$. Within the definite flower visitor category $80 \%$ of recorded flower visits were attributed to six species, only two of which were recorded in all nine studies, with the remainder only recorded in between five and eight studies, despite all being large Andrena or Bombus species, generally identified and quantified in all field studies. The likely and possible visitor categories were entirely comprised of Andrena or Halictidae species, two of which are oligolectic on Brassicaceae. 

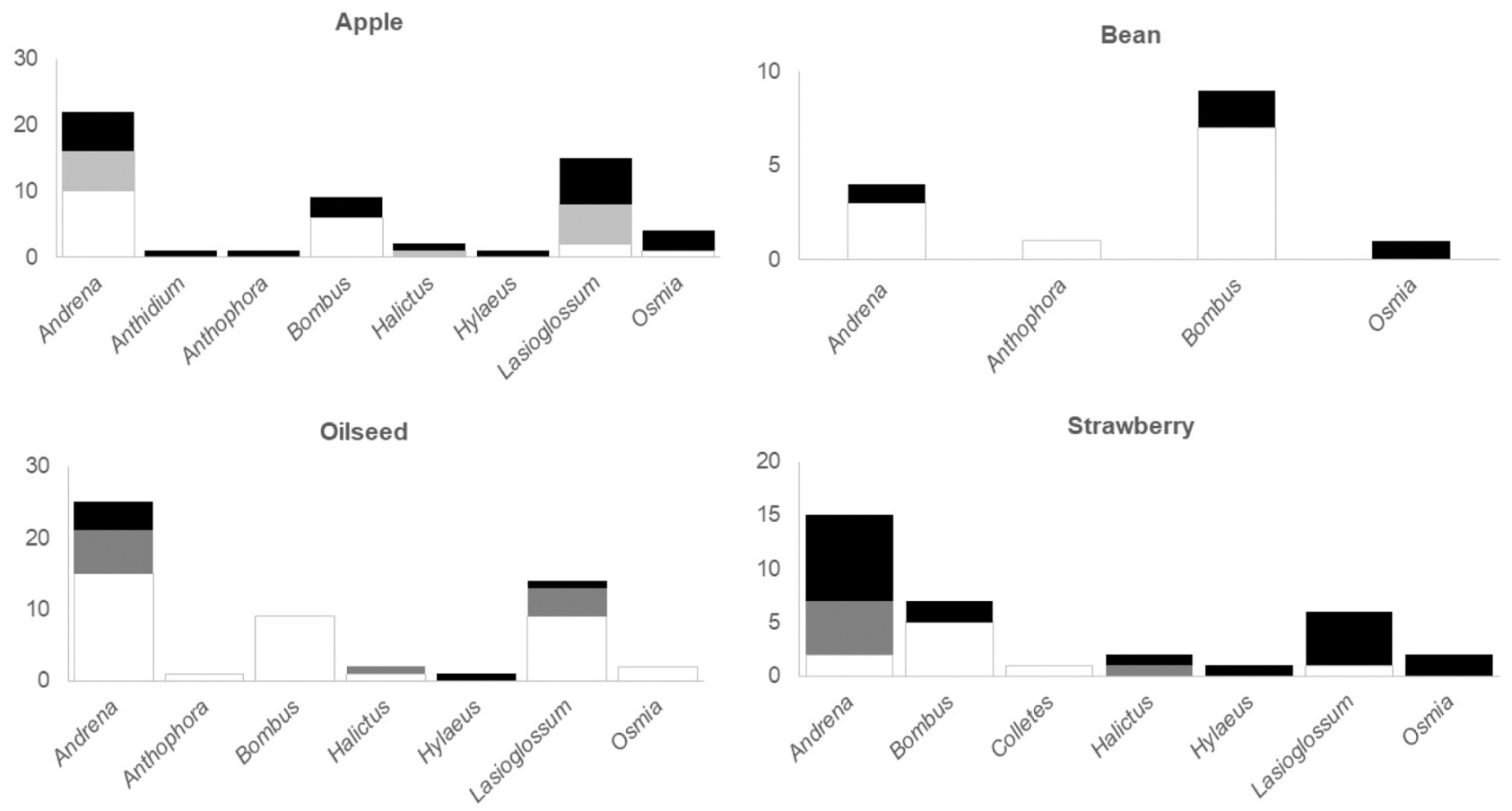

Fig. 3. The number of bee species from each genus which were categorised as definite $\square \quad$ likely

\subsubsection{Strawberry}

Two British strawberry flower visitor studies recorded all bees to species level. The remaining three only recorded a group of large Andrena and Bombus to species. Bombus species were the most common genus of bee within the definite flower visitor category $(n=5)$, but joint second as the most frequent genus overall, alongside Lasioglossum ( $\mathrm{n}=7$ ), with Andrena species being the most prevalent genus across all categories $(n=14)$. Within the definite flower visitor category $80 \%$ of

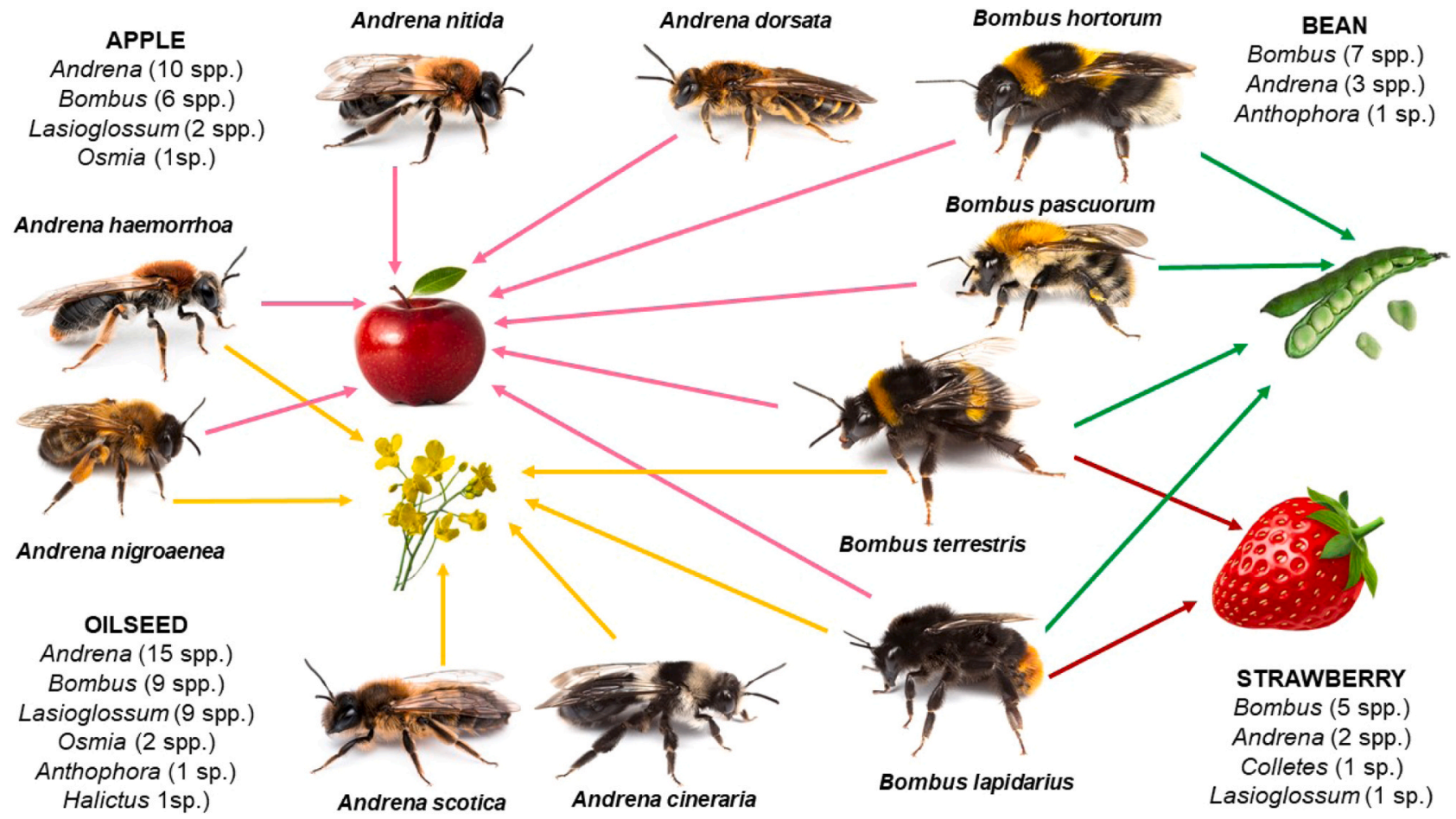

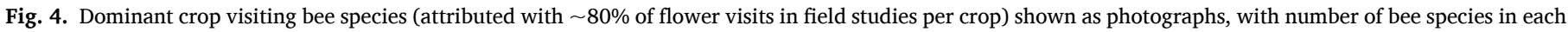
genus that are 'definite' flower visitors for each crop. 
recorded flower visits were attributed to just two Bombus species, which along with two other Bombus, were the only species recorded in more than two studies. The likely visitor category was almost exclusively represented by Andrena species. The possible visitor category was largely comprised of solitary bees from five different genera.

\subsection{Dominant crop flower visitors}

Ten bee species were attributed with $80 \%$ of flower visits across the four crops (Fig. S2; Fig. 4). There were differences however in the number and composition of those species making up the $80 \%$ of flower visits on a per crop basis. Differences in crop communities were even more distinct when considering the entire suite of bee species included in the characterisation of each crops' total flower visiting community (Figs. 3; 4). Wild bees were attributed with an average of between $63 \%$ and $83 \%$ of crop flower visits compared to honey bees (Apple: solitary bee visits $=68 \%$; Bean: solitary bee visits $=83 \%$; Oilseed: solitary bee visits $=63 \%$; Strawberry: solitary bee $=77 \%$ ).

\section{Discussion}

\subsection{Crop pollinator species}

Our study is the one of the first to evaluate the entire wild bee community of multiple crops on a national basis and can be used as model approach for other countries, crops and pollinators. With the identification of bee species important for pollinating crops we build the basis to better sustainably manage services with changing climate and land use. Whilst in accordance with other studies (Rader et al., 2012; Kleijn et al., 2015) our results indicate that a small proportion of common, generalist bee species do make the majority of crop flower visits, many more species were evidenced as crop flower visitors. Additionally, our results suggest that the contribution of wild bee species to crop flower visitation may be even greater than previously thought. Whereas previous estimates indicate that wild bees make a similar overall contribution to honey bees (Kleijn et al. 2015), when considering the entire suite of flower visiting species our results indicate that wild bees make on average between $63 \%$ and $83 \%$ of flower visits to our target crops. Given the benefits of biodiverse communities for current and future crop pollination services (Kremen et al., 2002; Hoehn et al., 2008; Garibaldi et al., 2011; Rader et al., 2012), interventions to support crop pollinators should target a more significant proportion of the bee fauna than at present (Wood et al., 2015b, 2016a; Gresty et al., 2018). Establishing a list of currently important, but also potentially relevant crop pollinators, is necessary to help target monitoring and conservation (Carvell et al., 2017).

Our results also support prior evidence of distinct differences in individual crop pollinator communities (Garratt et al., 2014a). The overwhelming majority of field bean and strawberry flower visits were attributed to bumblebees. However, whereas field bean was visited by the three longest tongued species in Britain, strawberry crops were almost exclusively visited by two other bumblebee species, with relatively shorter tongues. This supports a link between trait matching of bees and flowers in crop pollination (Garibaldi et al., 2015). Bombus species were also recorded visiting apple and oilseed rape. However, due to their low abundance in early spring during apple flowering (Martins et al., 2015), and lower rate of pollen transfer when visiting oilseed flowers (Woodcock et al., 2013) they are less important pollinators of these crops compared to solitary species. Andrena and Lasioglossum species were prevalent across both apple and oilseed flower visitor categories. Andrena are known to be highly efficient pollinators of both crops (Martins et al., 2015; Woodcock et al., 2013), especially apple (Russo et al., 2017). Most Lasioglossum, species however, generally emerge later than many Andrena species, and peak after apple flowering, whereas oilseed tends to flower later and longer, and Lasioglossum are likely important pollinators of this crop (Perrot et al., 2018; Catarino et al., 2019). Furthermore, we almost certainly significantly underestimated the diversity and abundance of Lasioglossum bees visiting oilseed rape, given that many studies did not include detailed quantitative data on this genus.

Our datasets also indicate that rare and specialist species may visit crop flowers when they are locally abundant or are especially attracted to crop flowers (MacLeod et al., 2020). Several rare species recorded in apple orchards are most common in south-east England, Britain's principal apple growing region, and bee species that are oligolectic on Brassicaceae were recorded in oilseed rape studies. Given that biodiversity benefits pollination (Dainese et al., 2019), strategies to support biodiverse crop communities may prove critical to sustain ecosystem service provision. Yet current agri-environment schemes options rarely consider rare species (Senapathi et al., 2015). There is however, a significant overlap in the floral resources used by common and rare crop pollinators (Sutter et al., 2017; MacLeod et al., 2020), and thus there are opportunities to promote both biodiversity and conservation in agricultural landscapes.

Our findings also offer an opportunity to anticipate potentially important future crop pollinators. For example, whilst a number of European crop flower visitors not presently recorded in British crop fields are currently geographically restricted, should they expand their range in the future, they could ameliorate the threat of ecological mismatches between current pollinators and crops due to climate change (Polce et al., 2013, 2014; Settele et al., 2016). Taken further, this information could be used to refine existing models of bee populations used to project pollinator populations at large spatial scales (e.g. Gardner et al., 2020), which can assist in larger scale planning of pollinator management.

Identifying specific bee crop pollinating species, as we have done, can inform refinements to agri-environment schemes to promote more biodiverse communities in agricultural landscapes. For example, Andrena were the most speciose genus of bees identified across flower visitor categories in three of the crops. Currently European agrienvironment measures to boost pollinator populations have focused on the creation of flower-rich habitats, including wildflower buffer strips (Wratten et al., 2012). Yet evidence suggests these are primarily visited by bumblebees, with solitary bees preferring non-sown, wild plants (Wood et al., 2015a, 2015b). In apple orchards for example, early-flying Andrena species have been positively associated with dandelions (Taraxacum agg.) rather than sown species, which often bloom later than apple flowers (Campbell et al., 2017). Reduced mowing regimes in orchards, and other crop areas, particularly in early spring could boost Andrena numbers and hence pollination. Such interventions are also likely to benefit early flying Lasioglossum, many species of which are known be attracted to yellow flowers in the family Asteraceae. Osmia species have also been demonstrated as efficient pollinators of apple, oilseed and strawberry crops (Abel et al., 2003; Garratt et al., 2016; Horth and Campbell, 2018), but as in this study, are frequently recorded in low numbers, likely due to a lack of suitable nesting and floral resources in agricultural landscapes for cavity nesting species (Gardner and Ascher, 2006; Blitzer et al., 2016). Incorporating hedgerow species such as Dog Rose and Bramble, alongside, areas of old and dead wood, around crop areas would provide both forage and nesting resources (Else and Edwards, 2018; Gresty et al., 2018) for these and other cavity nesting bees. Future management to support long-tongued solitary bees could benefit field bean pollination. Anthophora plumipes, for example, prefers to nest in vertical soil profiles, which are not currently a common feature in agricultural landscapes.

\subsection{Data constraints and limitations}

There are caveats to using foraging ecology to identify potential bee pollinators, as done here and elsewhere (Ahrenfeldt et al., 2015). There is a lack of published data for many bee species and others visit a wider range of flowers than can be realistically documented (Else and 
Edwards, 2018). As such, determining the status of bee species as crop flower visitors requires field survey data for confirmation. Yet comprehensive crop pollinator data is currently lacking as sampling is irregular, undertaken almost exclusively as part of bespoke research projects rather than systematic monitoring (Breeze et al., 2020). Furthermore, whilst census methods can provide information on floral associations, they require experienced surveyors to comprehensively record species richness (O'Connor et al., 2019). Across all four crops the only bees which were consistently identified to species level were large, conspicuous ones from the genera Bombus and Andrena. Small and inconspicuous species, particularly from the genus Lasioglossum, were often only extensively sampled in the pan trap surveys. Additionally, whilst the visitation rate of dominant species is strongly correlated to pollination service delivery (Winfree et al., 2015; Fijen et al., 2018), the assumption here and elsewhere that quantitative visitation data can be used to infer pollination (Kleijn et al., 2015), neglects to factor in that flower visitation alone is not a perfect proxy for pollination (King et al., 2013; Senapathi et al., 2015; Ollerton, 2017). Certain physiological and behavioural traits also influence pollination service delivery (Martins et al., 2015). Further detailed data and research is required before any definitive conclusions can be made about the contributions of individual bee species to crop pollination.

\section{Conclusions}

Given the importance of wild pollinators and the detrimental impacts of conventional agriculture on their populations it is unsurprising that the management of wild and managed pollinating insects is considered a critical step for future food security (Garibaldi et al., 2019; Kleijn et al., 2019; Rollin and Garibaldi et al., 2019; Reilly et al., 2020). Yet information on which species contribute most to ecosystem service delivery has long been elusive (Kremen and Chaplin-Kramer, 2007) despite its critical importance for both monitoring and conservation measures. Here we combine ecological and field data to provide a uniquely comprehensive overview of the crop pollinating bees of a single region, Great Britain. Whilst we have focused on Great Britain, a similar approach would be applicable across Europe, and could also be applied to non-bee species that have been identified as important crop pollinators (Rader et al., 2016). Our research bolsters evidence that many wild bee species, including rare and specialised ones, may contribute to crop pollination (Klein et al., 2003; Sutter et al., 2017; Winfree et al., 2018; MacLeod et al., 2020), thus it can be argued that agri-environment scheme options should not focus solely on dominant crop pollinators.

Future climatic changes threaten to further deplete already impoverished bee populations (Soroye et al., 2020) and create spatial mismatches between crops and their pollinators, which could exacerbate existing pollination deficits (Polce et al., 2014). To that end, the species identified as possible crop pollinators could represent an as yet untapped pollinator resource. Whilst some species may not currently visit crops due to ecological or environmental constraints, they could be assisted to expand by dedicated conservation measures in agricultural landscapes, allowing them to compensate for any declines in current crop pollinating species. Many such species are solitary, which presently benefit much less from agri-environment schemes than social species (Wood et al., 2015b, 2016a, 2016b; Gresty et al., 2018). As such land managers may need to re-evaluate existing pollinator management interventions and consider a broader range of species to safeguard the ecosystem service of crop pollination in an uncertain future.

\section{Funding}

LH was funded by NERC QMEE CDT. EJB was funded by a BBSRC Ph. D. studentship under grant BB/F016581/1. LB was was supported by the Scholarship Program of the German Federal Environmental Foundation (Deutsche Bundesstiftung Umwelt, DBU, AZ 20014/302). AJC was funded by the BBSRC and Syngenta UK as part of a case award Ph.D. (grant no. 1518739). AE was funded by the Swiss National Science Foundation (grant number 405940-115642). DG and A-MK were funded by grant PCIN2014-145-C02-02 (MinECo; EcoFruit project BiodivERsAFACCE2014-74). MG was supported by Establishing a UK Pollinator Monitoring and Research Partnership (PMRP) a collaborative project funded by Defra, the Welsh and Scottish Governments, JNCC and project partners'. GAdG was funded via research projects BO-11-011.01-051 and BO-43-011.06-007, commissioned by the Dutch Ministry of Agriculture, Nature and Food Quality. DK was funded by the Dutch Ministry of Economic Affairs (BO-11-011.01-011). AK-H was funded by the NKFIH project (FK123813), the Bolyai János Fellowship of the MTA, the ÚNKP-19-4-SZIE-3 New National Excellence Program of the Ministry for Innovation and Technology, and together with RF by the Hungarian Scientific Research Fund OTKA 101940. MM was funded by Waitrose \& Partners, Fruition PO, and the University of Worcester. MM was funded by grant INIA-RTA2013-00139-C03-01 (MinECo and FEDER). BBP and RFS were funded by the UK Natural Environment Research Council as part of Wessex BESS (ref. NE/J014680/1). NJV was funded by the Walloon Region (Belgium) Direction générale opérationnelle de l'Agriculture, des Ressources naturelles et de l'Environnement (DGO3) for the "Modèle permaculturel" project on biodiversity in micro-farms, FNRS/ FWO joint programme EOS - Excellence Of Science CliPS: Climate change and its impact on Pollination Services (project 30947854)". CW was funded by the Deutsche Forschungsgemeinschaft (DFG) (Project number 405945293). BW was funded by the Natural Environment Research Council (NERC) under research programme NE/N018125/1 ASSIST - Achieving Sustainable Agricultural Systems www.assist.ceh. ac.uk. TB and TO are supported by BBSRC, NERC, ESRC and the Scottish Government under the Global Food Security Programme (Grant BB/ R00580X/1). MG and data collection was funded by Insect Pollinators Initiative funded jointly by a grant from BBSRC, Defra, NERC, the Scottish Government and the Wellcome Trust, under the Living with Environmental Change Partnership and the Sustainable Management of Orchard Pollination Services Project.

\section{CRediT authorship contribution statement}

LH conceived the ideas, analysed the data and wrote the manuscript. MG, TB and TO contributed to the conceptual development and manuscript revisions. All other authors provided data and contributed to manuscript revisions.

\section{Declaration of Competing Interest}

The authors declare that they have no known competing financial interests or personal relationships that could have appeared to influence the work reported in this paper.

\section{Acknowledgements}

Thank you to Jean-Marc Molenberg for assistance in field surveys and specimen curation for the apple data collection in Belgium. Thanks to Ignasi Bartomeus for providing additional field survey data. Also thank you to Samantha Ardin, D.A. Bond, Hannah Feltham, Harriet Griffin, E.J.M. Kirby, Jean-Noel Tasei and Verena Riedinger for published crop field survey data that were used in analyses.

Fig. 1 - Crop map courtesy of Alice Haughan, University of Reading.

Fig. 4 - Bee photographs courtesy of Nicolas J. Vereecken and Stéphane De Greef.

\section{Appendix A. Supporting information}

Supplementary data associated with this article can be found in the online version at doi:10.1016/j.agee.2021.107447. 


\section{References}

Abel, C.A., Wilson, R.L., Luhman, R.L., 2003. Pollinating efficacy of Osmia cornifrons and Osmia lignaria subsp. lignaria (Hymenoptera: Megachilidae) on three Brassicaceae species grown under field cages. J. Ėntomol. Sci. 38 (4), 545-552.

Ahrenfeldt, E.J., Klatt, B.K., Arildsen, J., Trandem, N., Andersson, G.K.S., Tscharntke, T., Sigsgaard, L, 2015. Pollinator communities in strawberry crops-variation at multiple spatial scales. Bull. Èntomol. Res. 105 (4), 497-506.

Aizen, M.A., Harder, L.D., 2009. The global stock of domesticated honey bees is growing slower than agricultural demand for pollination. Curr. Biol. 19, 915-918.

Bartomeus, I., Potts, S.G., Steffan-Dewenter, I., Vaissiere, B.E., Woyciechowski, M., Krewenka, K.M., Bommarco, R., 2014. Contribution of insect pollinators to crop yield and quality varies with agricultural intensification. PeerJ 2, e328.

Blitzer, E.J., Gibbs, J., Park, M.G., Danforth, B.N., 2016. Pollination services for apple are dependent on diverse wild bee communities. Agric. Ecosyst. Environ. 221, 1-7.

Bond, D.A., Kirby, E.J.M., 1999. Anthophora plumipes (Hymenoptera: Anthophoridae) as a pollinator of broad bean (Vicia faba major). J. Apic. Res. 38 (3-4), 199-203.

Bossert, S., 2015. Recognition and identification of species in the Bombus lucorumcomplex-a review and outlook. bioRxiv, 011379.

Breeze, T.D., Vaissière, B.E., Bommarco, R., Petanidou, T., Seraphides, N., Kozák, L., Moretti, M., 2014. Agricultural policies exacerbate honeybee pollination service supply-demand mismatches across Europe. PloS One 9, e82996.

Breeze, T.D., Bailey, A.P., Balcombe, K.G., Brereton, T., Comont, R., Edwards, M., Carvell, C., 2020. Pollinator monitoring more than pays for itself. J. Appl. Ecol.

BWARS, 2020. Bees, wasps \& ants recording society. 〈https://www.bwars.com/home .

Campbell, A.J., Wilby, A., Sutton, P., Wäckers, F.L., 2017. Do sown flower strips boost wild pollinator abundance and pollination services in a spring-flowering crop? A case study from UK cider apple orchards. Agric. Ecosyst. Environ. 239, 20-29.

Carvell, C., Isaac, N., Jitlal, M., Peyton, J., Powney, G., Roy, D., Roy, H., 2017. Design and testing of a national pollinator and pollination monitoring framework (Technica Report). Department for Environment, Food and Rural Affairs.

Catarino, R., Bretagnolle, V., Perrot, T., Vialloux, F., Gaba, S., 2019. Bee pollination outperforms pesticides for oilseed crop production and profitability. Proc. R. Soc. B Biol. Sci. 286 (1912), 20191550.

Dainese, M., Martin, E.A., Aizen, M., Albrecht, M., Bartomeus, I., Bommarco, R. Ghazoul, J., 2019. A global synthesis reveals biodiversity-mediated benefits for crop production. bioRxiv, 554170 .

Else, G.R., Edwards, M., 2018. Handbook of the Bees of the British Isles, vol. 2. Ray Society.

Else, G.R., Bolton, B., Broad, G.R., 2016. Checklist of British and Irish hymenopteraaculeates (Apoidea, Chrysidoidea and Vespoidea). Biodivers. Data J. 4.

Fijen, T.P., Scheper, J.A., Boom, T.M., Janssen, N., Raemakers, I., Kleijn, D., 2018. Insect pollination is at least as important for marketable crop yield as plant quality in a seed crop. Ecol. Lett. 21 (11), 1704-1713.

Gardner, E., Breeze, T.D., Clough, Y., Smith, H., Baldock, K., Campbell, A., Oliver, T., 2020. Reliably predicting pollinator abundance: challenges of calibrating processbased ecological models. Methods Ecol. Evol. 11, 1673-1689.

Gardner, K.E., Ascher, J.S., 2006. Notes on the native bee pollinators in New York apple orchards. J. N. Y. Ėntomol. Soc. 114 (1), 86-91.

Garibaldi, L.A., Steffan-Dewenter, I., Kremen, C., Morales, J.M., Bommarco, R., Cunningham, S.A., Holzschuh, A., 2011. Stability of pollination services decreases with isolation from natural areas despite honey bee visits. Ecol. Lett. 14 (10), 1062-1072.

Garibaldi, L.A., Bartomeus, I., Bommarco, R., Klein, A.M., Cunningham, S.A., Aizen, M. A., Morales, C.L., 2015. Trait matching of flower visitors and crops predicts fruit se better than trait diversity. J. Appl. Ecol. 52, 1436-1444.

Garibaldi, L.A., Pérez-Méndez, N., Garratt, M.P., Gemmill-Herren, B., Miguez, F.E., Dicks, L.V., 2019. Policies for ecological intensification of crop production. Trends Ecol. Evol. 34 (4), 282-286.

Garratt, M.P., Coston, D.J., Truslove, C.L., Lappage, M.G., Polce, C., Dean, R., Potts, S.G., 2014a. The identity of crop pollinators helps target conservation for improved ecosystem services. Biol. Conserv. 169, 128-135.

Garratt, M.P., Breeze, T.D., Jenner, N., Polce, C., Biesmeijer, J.C., Potts, S.G., 2014b، Avoiding a bad apple: Insect pollination enhances fruit quality and economic value. Agric. Ecosyst. Environ. 184, 34-40.

Garratt, M.P.D., Breeze, T.D., Boreux, V., Fountain, M.T., Mckerchar, M., Webber, S.M., Biesmeijer, J.C., 2016. Apple pollination: demand depends on variety and supply depends on pollinator identity. PloS One 11 (5), e0153889.

Garratt, M.P.D., Potts, S.G., Banks, G., Hawes, C., Breeze, T.D., O'Connor, R.S., Carvell, C., 2019. Capacity and willingness of farmers and citizen scientists to monitor crop pollinators and pollination services. Glob. Ecol. Conserv. 20, e00781.

Godfray, H.C.J., Garnett, T., 2014. Food security and sustainable intensification. Philos. Trans. R. Soc. B Biol. Sci. 369, 20120273.

Grab, H., Branstetter, M.G., Amon, N., Urban-Mead, K.R., Park, M.G., Gibbs, J., Danforth, B.N., 2019. Agriculturally dominated landscapes reduce bee phylogenetic diversity and pollination services. Science 363 (6424), 282-284.

Gresty, C.E., Clare, E., Devey, D.S., Cowan, R.S., Csiba, L., Malakasi, P., Willis, K.J., 2018. Flower preferences and pollen transport networks for cavity-nesting solitary bees: Implications for the design of agri-environment schemes. Ecol. Evol. 8 (5), 7574-7587.

Hoehn, P., Tscharntke, T., Tylianakis, J.M., Steffan-Dewenter, I., 2008. Functional group diversity of bee pollinators increases crop yield. Proc. R. Soc. Lond. B Biol. Sci. 275 (1648), 2283-2291.

Horth, L., Campbell, L.A., 2018. Supplementing small farms with native mason bees increases strawberry size and growth rate. J. Appl. Ecol. 55 (2), 591-599.
IPBES, 2016. Deliverable 3a: thematic assessment of pollinators, pollination and food production. 〈http://www.ipbes.net/sites/default/files/downloads/pdf/3a_pollina tion_individual_chapters_20161124.pdf $\rangle$.

King, C., Ballantyne, G., Willmer, P.G., 2013. Why flower visitation is a poor proxy for pollination: measuring single-visit pollen deposition, with implications for pollination networks and conservation. Methods Ecol. Evol. 4 (9), 811-818.

Kleijn, D., Winfree, R., Bartomeus, I., Carvalheiro, L.G., Henry, M., Isaacs, R., Ricketts, T. H., 2015. Delivery of crop pollination services is an insufficient argument for wild pollinator conservation. Nat. Commun. 6, 7414.

Kleijn, D., Bommarco, R., Fijen, T.P., Garibaldi, L.A., Potts, S.G., van der Putten, W.H., 2019. Ecological intensification: bridging the gap between science and practice. Trends Ecol. Evol. 34 (2), 154-166.

Klein, A.M., Steffan-Dewenter, I., Tscharntke, T., 2003. Fruit set of highland coffee increases with the diversity of pollinating bees, Proceedings of the Royal Society of London. Series B: Biological Sciences, 270(1518), 955-961.

Kremen, C., Chaplin-Kramer, R., 2007. Insects as providers of ecosystem services: crop pollination and pest control, in: Insect conservation biology: proceedings of the royal entomological society's 23rd symposium, 349-382, Wallingford, UK: CABI Publishing.

Kremen, C., Williams, N.M., Thorp, R.W., 2002. Crop pollination from native bees at risk from agricultural intensification. Proc. Natl. Acad. Sci. 99 (26), 16812-16816.

MacLeod, M., Reilly, J., Cariveau, D.P., Genung, M.A., Roswell, M., Gibbs, J., Winfree, R., 2020. How much do rare and crop-pollinating bees overlap in identity and flower preferences? J. Appl. Ecol. 57 (2), 413-423.

Martins, K.T., Gonzalez, A., Lechowicz, M.J., 2015. Pollination services are mediated by bee functional diversity and landscape context. Agric. Ecosyst. Environ. 200, 12-20. Michener, C.D., 2000. The Bees of the World, vol. 1. JHU press.

O'Connor, R.S., Kunin, W.E., Garratt, M.P., Potts, S.G., Roy, H.E., Andrews, C., Morris, R. K., 2019. Monitoring insect pollinators and flower visitation: the effectiveness and feasibility of different survey methods. Methods Ecol. Evol. 10 (12), 2129-2140.

Oliver, T.H., Heard, M.S., Isaac, N.J., Roy, D.B., Procter, D., Eigenbrod, F., Proença, V., 2015. Biodiversity and resilience of ecosystem functions. Trends Ecol. Evol. 30 (11), 673-684.

Ollerton, J., 2017. Pollinator diversity: distribution, ecological function, and conservation. Annu. Rev. Ecol. Evol. Syst. 48, 353-376.

Perrot, T., Gaba, S., Roncoroni, M., Gautier, J.L., Bretagnolle, V., 2018. Bees increase oilseed rape yield under real field conditions. Agric. Ecosyst. Environ. 266, 39-48.

Polce, C., Termansen, M., Aguirre-Gutiérrez, J., Boatman, N.D., Budge, G.E., Crowe, A., Somerwill, K.E., 2013. Species distribution models for crop pollination: a modelling framework applied to Great Britain. PloS One 8 (10), e76308.

Polce, C., Garratt, M.P., Termansen, M., Ramirez-Villegas, J., Challinor, A.J., Lappage, M. G., Somerwill, K.E., 2014. Climate-driven spatial mismatches between British orchards and their pollinators: increased risks of pollination deficits. Glob. Change Biol. 20 (9), 2815-2828.

Powney, G.D., Carvell, C., Edwards, M., Morris, R.K., Roy, H.E., Woodcock, B.A., Isaac, N.J., 2019. Widespread losses of pollinating insects in Britain. Nat. Commun. 10 (1), 1018.

Rader, R., Howlett, B.G., Cunningham, S.A., Westcott, D.A., Edwards, W., 2012. Spatial and temporal variation in pollinator effectiveness: do unmanaged insects provide consistent pollination services to mass flowering crops? J. Appl. Ecol. 49 (1), $126-134$.

Rader, R., Bartomeus, I., Garibaldi, L.A., Garratt, M.P., Howlett, B.G., Winfree, R., Bommarco, R., 2016. Non-bee insects are important contributors to global crop pollination. Proc. Natl. Acad. Sci. 113 (1), 146-151.

Reilly, J.R., Artz, D.R., Biddinger, D., Bobiwash, K., Boyle, N.K., Brittain, C., Ellis, J.D., 2020. Crop production in the USA is frequently limited by a lack of pollinators. Proc. R. Soc. B Biol. Sci. 287 (1931), 20200922.

Russo, L., Park, M.G., Blitzer, E.J., Danforth, B.N., 2017. Flower handling behavior and abundance determine the relative contribution of pollinators to seed set in apple orchards. Agric. Ecosyst. Environ. 246, 102-108.

Scheper, J., Holzschuh, A., Kuussaari, M., Potts, S.G., Rundlöf, M., Smith, H.G., Kleijn, D., 2013. Environmental factors driving the effectiveness of European agrienvironmental measures in mitigating pollinator loss-a meta-analysis. Ecol. Lett. 16 (7), 912-920.

Senapathi, D., Biesmeijer, J.C., Breeze, T.D., Kleijn, D., Potts, S.G., Carvalheiro, L.G., 2015. Pollinator conservation - the difference between managing for pollination services and preserving pollinator diversity. Curr. Opin. Insect Sci. 12, 93-101.

Settele, J., Bishop, J., Potts, S.G., 2016. Climate change impacts on pollination. Nat. Plants 2 (7), 16092.

Soroye, P., Newbold, T., Kerr, J., 2020. Climate change contributes to widespread declines among bumble bees across continents. Science 367 (6478), 685-688.

Sutter, L., Jeanneret, P., Bartual, A.M., Bocci, G., Albrecht, M., 2017. Enhancing plant diversity in agricultural landscapes promotes both rare bees and dominant croppollinating bees through complementary increase in key floral resources. J. Appl. Ecol. 54 (6), 1856-1864.

Tonietto, R.K., Larkin, D.J., 2018. Habitat restoration benefits wild bees: a meta-analysis. J. Appl. Ecol. 55 (2), 582-590.

Vanbergen, A.J., Heard, M.S., Breeze, T., Potts, S.G., Hanley, N., 2014. Status and value of pollinators and pollination services. /http://nora.nerc.ac.uk/id/eprint/505259/).

Vázquez, D.P., Morris, W.F., Jordano, P., 2005. Interaction frequency as a surrogate for the total effect of animal mutualists on plants. Ecol. Lett. 8 (10), 1088-1094.

Webb, J., Heaver, D., Lott, D., Dean, H.J., van Breda, J., Curson, Foster, G., 2018. Pantheon - database version 3.7.6. 〈https://www.brc.ac.uk/pantheon/>.

Westphal, C., Bommarco, R., Carré, G., Lamborn, E., Morison, N., Petanidou, T., Vaissière, B.E., 2008. Measuring bee diversity in different European habitats and biogeographical regions. Ecol. Monogr. 78 (4), 653-671. 
Winfree, R., Fox, W., Williams, J., Reilly, N.M., J.R, Cariveau, D.P., 2015. Abundance of common species, not species richness, drives delivery of a real-world ecosystem service. Ecol. Lett. 18 (7), 626-635.

Winfree, R., Reilly, J.R., Bartomeus, I., Cariveau, D.P., Williams, N.M., Gibbs, J., 2018 Species turnover promotes the importance of bee diversity for crop pollination at regional scales. Science 359 (6377), 791-793.

Wolf, S., Rohde, M., Moritz, R.F., 2010. The reliability of morphological traits in the differentiation of Bombus terrestris and B. lucorum (Hymenoptera: Apidae). Apidologie 41 (1), 45-53.

Wood, T.J., Holland, J.M., Hughes, W.O., Goulson, D., 2015a. Targeted agri-environment schemes significantly improve the population size of common farmland bumblebee species. Mol. Ecol. 24 (8), 1668-1680.

Wood, T.J., Holland, J.M., Goulson, D., 2015b. Pollinator-friendly management does not increase the diversity of farmland bees and wasps. Biol. Conserv. 187, 120-126.
Wood, T.J., Holland, J.M., Goulson, D., 2016a. Providing foraging resources for solitary bees on farmland: current schemes for pollinators benefit a limited suite of species. J. Appl. Ecol. 54 (1), 323-333.

Wood, T.J., Holland, J.M., Goulson, D., 2016b. Diet characterisation of solitary bees on farmland: dietary specialisation predicts rarity. Biodivers. Conserv. 25 (13), 2655-2671.

Woodcock, B.A., Edwards, M., Redhead, J., Meek, W.R., Nuttall, P., Falk, S., Pywell, R.F., 2013. Crop flower visitation by honeybees, bumblebees and solitary bees: behavioural differences and diversity responses to landscape. Agric. Ecosyst. Environ. 171, 1-8.

Woodcock, B.A., Garratt, M.P.D., Powney, G.D., Shaw, R.F., Osborne, J.L., Soroka, J., Jauker, F., 2019. Meta-analysis reveals that pollinator functional diversity and abundance enhance crop pollination and yield. Nat. Commun. 10 (1), 1-10.

Wratten, S.D., Gillespie, M., Decourtye, A., Mader, E., Desneux, N., 2012. Pollinator habitat enhancement: benefits to other ecosystem services. Agric. Ecosyst. Environ, $159,112-122$. 